\title{
心房細動を合併した冠動脈疾患症例に対する手術治療戦略
}

\author{
秦＼cjkstart広樹，小林順二郎
}

Hiroki Hata, Junjiro Kobayashi: Strategy for concomitant surgery for atrial fibrillation in coronary artery bypass grafting patients. J Jpn Coron Assoc 2013; 19: 90-94

\section{I. 心房細動の疫学}

心房細動 (atrial fibrillation; AF) は最も頻度の高い持続性 不整脈である. $\mathrm{AF}$ の有病率は男女とも加齢とともに増 し, 特に 60 歳を超えると急に増大する ${ }^{1}$. 米国の研究で は成人の $\mathrm{AF}$ 有病率は $0.95 \%$ とされ22), 本邦では $0.56 \%$ 程 度との報告がある ${ }^{3)}$ 。また時代の変化に伴って有病率の変 化が認められ, Framingham 研究では 1960 年代後半に比し て 1980 年代後半では男性の $\mathrm{AF}$ 有病率は約 3 倍に増加し ていると報告している4). AFの基礎疾患としては高血 圧, 弁膜症, 虚血性心疾患などが挙げられるが調査の年 代，母集団，人種差などによって差がある5).

\section{II. 心房細動患者と冠動脈疾患}

欧米では AF の背景に冠動脈疾患 (coronary artery disease;

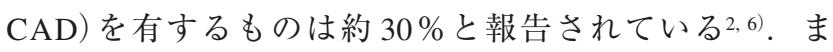
た， $\mathrm{AF}$ 患者では $\mathrm{CT}$ アンギオ検查上での冠動脈病変が約 半数に認められ洞調律患者群に比して有意に高率であっ たとする報告が最近発表され注目されている7). 我が国で 行われた J-RHYTHM 試験では, CAD 合併率は発作性 AF で 7.4\%, 持続性 $\mathrm{AF}$ で $6.1 \%$ というものであった ${ }^{8)}$. 心筋 虚血と AF の発症に有意な関連があることは広く認識され ており相対リスクは狭心症で 2.8 倍, 心筋梗塞で 3.6 倍と され，このリスクは虚血発症時に最も高くその後経過と ともに減少する9)とされるが，心筋虚血時に AFが生じる 機序については未だに完全には解明されていない。 た だ，狭心症や心筋梗塞に $\mathrm{AF}$ を併発すると心拍数の増加, 心拍出量の低下により病態を悪化させうるため, 治療の 原則は心筋虚血の改善に加え $\mathrm{AF}$ を解消することである.

\section{III. 心房細動を伴う冠動脈病変の治療方針}

まず, $\mathrm{AF}$ の外科的手術適応として, 日本循環器学会,

国立循環器病研究センター心藏血管外科 ( $\bar{T}$ 565-8565 大阪府吹 田市藤白台 5-7-1)

doi: 10.7793 /jcoron. 19.012
不整脈の非薬物療法ガイドライン 2011 年改訂版10)を Table 1 に示す．僧帽弁手術に AF 手術を併施することに より術後脳梗塞発生率の低下, 術後心機能改善および生 存率上昇を認めることが示されており 11,12), 前回のガイド ライン (2006 年度改訂版) から僧帽弁手術に AF 手術を併 施することがClass I と記載された。一方，僧帽弁手術以 外の心臓手術においても $\mathrm{AF}$ 手術を併施することにより, 術後 QOL の改善, 遠隔期成績の改善が期待でき13,14), ガ イドラインでもClass IIa となっている. 実際, 僧帽弁疾 患を合併していない症例では左房拡大が軽度で心不全の 程度も軽症の場合が多く, $\mathrm{AF}$ 手術の成功率が高い.

また，2010年に発表された ISMICS (International Society of Minimally Invasive Cardiothoracic Surgery)のステートメ ントでは弁膜症手術や冠動脈バイパス術 (coronary artery bypass grafting; $\mathrm{CABG}$ )に併施する $\mathrm{AF}$ 手術は脳合併症や塞 栓症を減らし長期予後を改善させうるとされ, Class IIa と されている15, 16).さらに 2012 年に発表された HRS/EHRA/ ECAS (Heart Rhythm Society/European Heart Rhythm Association/European Cardiac Arrhythmia Society)のステートメント でも同様に, 有症状で薬剤抵抗性もしくは薬剤導入後の $\mathrm{AF}$ に対する, 開心術での AF 手術併施は Class IIa (抗不整 脈薬導入後の慢性 $\mathrm{AF}$ のみ IIb) とされている17).

このように, 開心術施行時に $\mathrm{AF}$ 手術を施行することは 一定条件下では推奨されているが, $\mathrm{CAD}$ 症例に限ってみ ればそのエビデンスはどうであろうか。これまで前向き 無作為比較試験による十分なデー夕がなく， AFを伴う $\mathrm{CAD}$ 患者の治療方針に関しては内科的治療の是非も含め て未だに議論のあるところではあるが， AFについて外科 的介入をせずに CABG (on-pump もしくは off-pump)のみ 施行した場合，早期および遠隔成績が悪化したという報 告がなされている18-21)。一方, Damiano や Khargi らによ れば $\mathrm{AF}$ 合併 $\mathrm{CAD}$ 患者に対し on pump CABG と Maze を 併施した場合，手術死亡や合併症を増やさずに 75～98\% で洞調律を維持できたとし, on-pump CABGでは積極的 に Maze を併施するべきとしている22,23).

On-pump CABG+Maze という術式は AF 合併 CAD 患者 
J Jpn Coron Assoc 2013; 19: 90-94

Table 1 心房細動手術の適応

Class I :

僧帽弁疾患に合併した心房細動で, 僧帽弁に対する心臓手術を行う場合

Class IIa :

1. 僧帽弁以外の器質的心疾患に対する心臓手術を行う場合

2. 血栓溶解療法や抗凝固療法抵抗性の左房内血栓症の合併, あるいは適切な抗凝固 療法にもかかわらず左房内血检に起因する塞栓症の既往を有する場合

3. カテーテルアブレーションの不成功例あるいは再発例

Class IIlb :

1. 孤立性心房細動で, 動悸等の自覚症状が強く, QOL の著しい低下があり, 薬物治 療抵抗性または副作用のため使用不能な場合

2. 薬物治療が無効な発作性心房細動で, 除細動等の救急治療を繰り返している場合

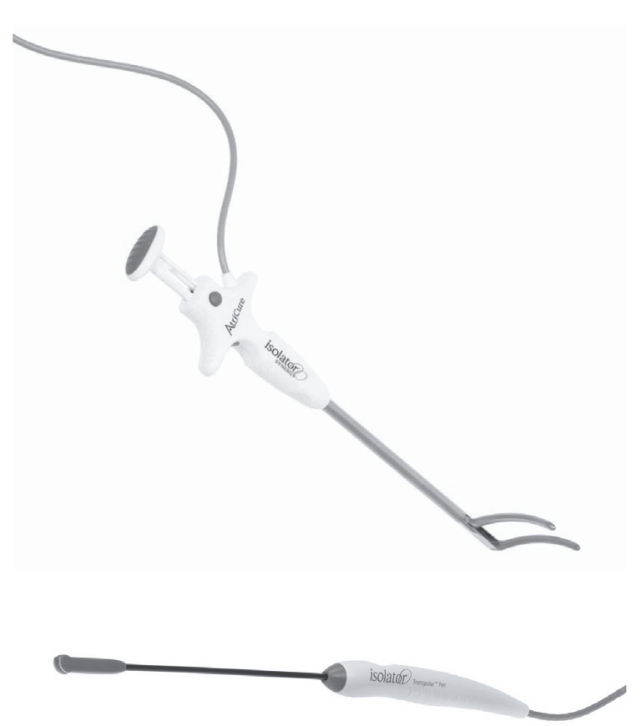

Fig. 1 双極高周波デバイス (AtriCure ${ }^{\circledR}$ Isolator Synergy, Isolator Transpolar Pen, AtriCure, Inc.)

に対して最も効果的であることは確かだが, 同時に最も 侵襲的であるともいえる. CABG 症例の約 $60 \%$ が offpump で行われている本邦では手術リスクが増大すること を考慮する必要がある.

\section{IV. “Off-pump” アブレーション}

近年，さまざまなアブレーションデバイスが臨床に導 入され， $\mathrm{AF}$ 手術が安全かつ容易に比較的短時間で行える ようになっただけではなく、いわゆる off-pumpでの AF 手術を可能とした，Off-pumpにおいて Cox-Mazeをする 試みもある24)が，一般的には肺静脈隔離(pulmonary vein isolation; PVI)が基本である. 別のアブレーションライン を追加したり左心耳閉鎖を合わせて施行したりする場合 もある.アアブレーションのエネルギーソースには, 古く から使われている凍結凝固 (cryo-ablation) に加え高周波, microwave, 超音波, 赤外線レーザーなどの焼灼エネル ギーがある．なかでも頻用されているのが双極高周波デ バイス (Fig. 1，2)であろう。心房切開を行わずに両側肺静

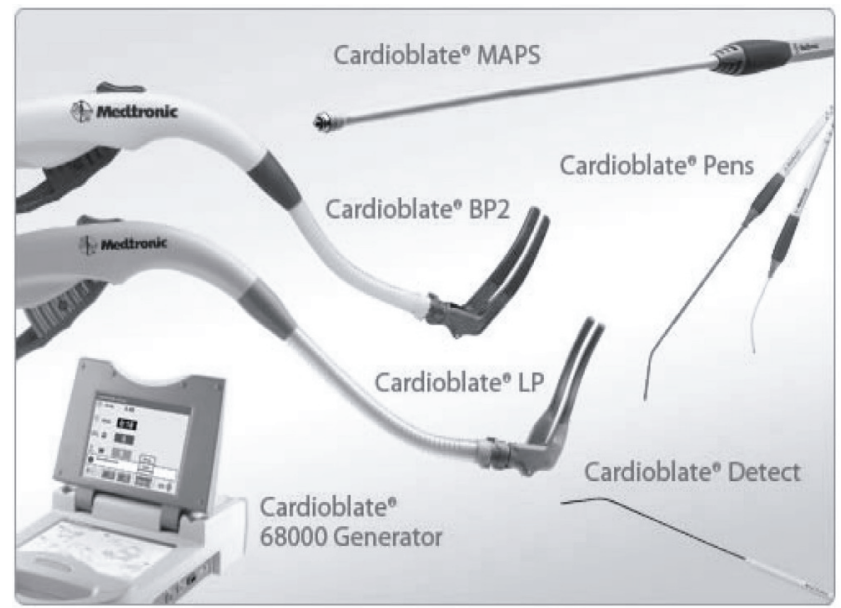

Fig. 2 双極高周波デバイス (Cardioblate ${ }^{\circledR}$, Medtronic, Inc.)

脈開口部の左房壁をジョーで挟んでジョーの両側の電極 間で高周波通電を行い, 必要に応じてペン型で追加ライ ンの焼灼を行う。 Off-pump PVIは比較的安全かつ容易に off-pump CABG に併施でき, 洞調律維持率も 70 90\%程 度とされる 25,26 が，心拡大症例や低左心機能症例では肺静 脈周囲の剝離や心臓脱転が困難な症例もあり注意を要す る.また, 1 回の通電では肺静脈が完全に電気的に隔離さ れないことも多く, 数回の通電の後, 肺静脈ペーシング を行って心房捕捉の有無を確認するのが確実である. な お，血行再建を先に行い虚血を解除してから PVIを行う 施設が多いようであるが PVI 操作時にグラフトに無理な テンションがかからないように注意が必要である。ま た，超音波や microwave による off-pump PVIを CABGに 併施した報告はそれほど多くはないものの, いずれもそ の安全性と有用性が報告されている27, 28).

Off-pump CABG に併施する off-pump PVI の成績を左右 する最も重要な因子の一つは AFのタイプである. そもそ も AFのトリガーは肺静脈内にあり, それが発作性に頻回 

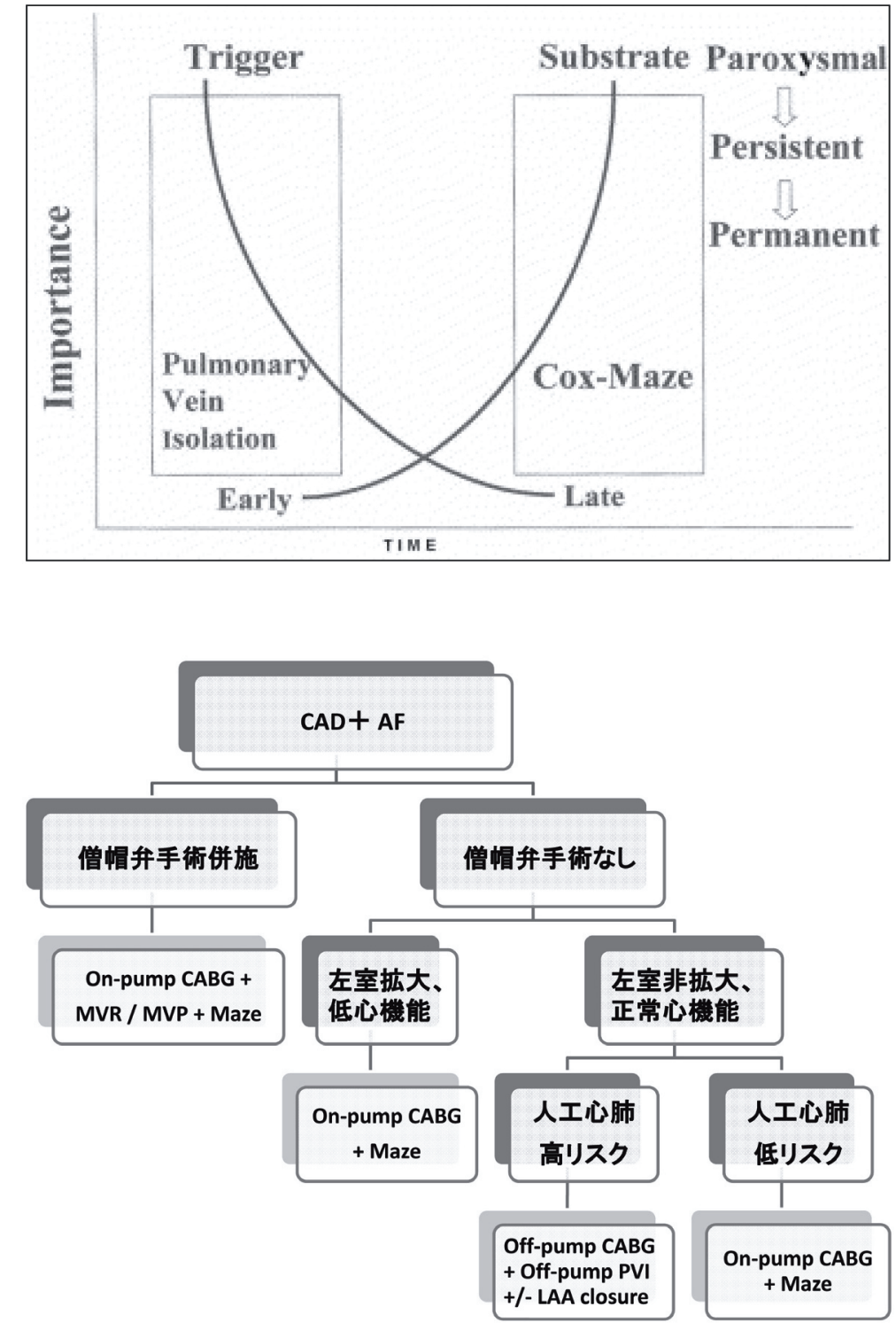

Fig. 3 時間経過とともに心房細動の電気生理学的機 序が異なり，症例ごとに術式を選択する必要がある (文献 26 より引用).
Fig. 4 当センターが考える心房細動合併冠動脈疾患 患者に対する手術治療戦略

発作性心房細動では full-MazeをPVIに簡略化しても よい.

CAD: coronary artery disease, AF: atrial fibrillation, CABG: coronary artery bypass grafting, MVR: mitral valve replacement, MVP: mitral valve plasty, PVI: pulmonary vein isolation, LAA: left atrial appendage
に fireすることで AF が発生するとされる29)。これは PVI により容易に抑えられるため, 発作性心房細動 (paroxys-

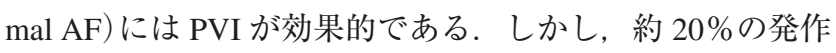
性心房細動は持続性心房細動 (persistent AF) へと移行し, さらに多くの場合 1 年後には永続性心房細動 (permanent $\mathrm{AF})$ となる。そうなった場合，心房組織はリモデリングと もいえる変化を来し, 単に PVIだけでは AFを制御でき ない可能性が高くなり, Cox-Mazeがより効果的である場

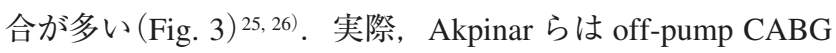
に併施した off-pump PVIの 1 年後の洞調律維持率は発作 性 $\mathrm{AF}$ 群で 83.3\%であったのに対し永続性 $\mathrm{AF}$ 群では $59 \%$ であったと報告26) し, Fukaharaらは同様のコホートで $100 \%$ 対 $20 \%$ であったと報告している30).

以上のことから，僧帽弁手術を併施しない $\mathrm{AF}$ 合併 $\mathrm{CAD}$ 患者に対しては, 人工心肺使用や心停止が大きなリ スクとならないような症例や心拡大や低心機能のため off- pump CABG が適さない症例では on-pump CABG+Maze と いう術式が有用と思われ，心機能正常で人工心肺のハイ リスク症例では off-pump CABG+off-pump PVIを考慮して もよいと考えられる. また, 発作性心房細動の症例では いわゆる full-MazeをPVIのみに簡略化することも可能と 考える. 当センターが考える $\mathrm{AF}$ 合併 $\mathrm{CAD}$ 患者の治療入 トラテジーを Fig. 4 に示す.

\section{V. 左心耳閉鎖}

血栓塞栓症は $\mathrm{AF}$ の最も重要な合併症であり, 多くは左 心耳内血栓が原因となる。 それゆえ, 脳梗塞などの塞栓 症予防のため $\mathrm{AF}$ 患者で開心術時に左心耳を閉鎖すること はルーチンとなっていると思われる．左房を切開する場 合は内腔から縫合閉鎖するケースもあるが, 左房を切開 せずに先端を切離し左心耳にアブレーションを行って断 端を縫合閉鎖する場合も多く，これはいわゆる on-pump 
beating でも可能である. Off-pump では手技上の問題や出 血のリスクも考慮し，心耳を切開せずに基部を結紮する か放置されるケースが多いと思われる。本邦ではまだ導 入されていないが欧米では off-pump でも容易かつ安全に 左心耳を閉鎖できるクリップ(AtriClip, Atricure, Inc.)が臨 床応用されており ${ }^{31,32)}$, 優れた脳合併症予防効果だけでは なく左心耳の電気的隔離効果も認められている ${ }^{33)}$. 同ク リップは後述する MICS (minimally invasive cardiac surgery) にも応用でき, 本邦での導入が待たれる.

\section{VI. さらなる低侵襲の試み}

さらなる低侵襲を目的として, 最近では胸腔鏡補助下 に off-pump PVIを施行するいわゆる MICS PVIも行われ ている. 専ら lone AFに対して施行され, その安全性とと もに開胸下での PVI と変わらない洞調律維持率が報告さ れている ${ }^{34,35)}$.さらに 2009 年には Totsugawa らが, MIDCAB (minimally invasive direct coronary artery bypass) と MICS PVIを併施した症例を初めて報告した ${ }^{36)}$. 執刀医は MIDCAB と MICS PVI それぞれの手術手技に習熟する必 要があり, また適応症例は限られるものの, 今後かかる 症例は増加するものと考えられる。

$$
\text { VII. まとめ }
$$

AFを合併するCAD 患者の治療戦略について概説し た. AF 根治の観点からは CABG+Maze が効果的ではある が, off-pump CABG+off-pump PVI が妥当な症例もあり, 症例ごとに治療方針を検討する必要がある. AF 手術のデ バイスは進化を続けており，今後ますます低侵襲手術の 方向に進むことが予想される.

\section{文献}

1) Feinberg WM, Blackshear JL, Laupacis A, Kronmal R, Hart RG: Prevalence, age distribution, and gender of patients with atrial fibrillation. Analysis and implications. Arch Intern Med 1995; 155: 469-473

2) Go AS, Hylek EM, Phillips KA, Chang Y, Henault LE, Selby JV, Singer DE: Prevalence of diagnosed atrial fibrillation in adults: national implications for rhythm management and stroke prevention: the AnTicoagulation and Risk Factors in Atrial Fibrillation (ATRIA) Study. JAMA 2001; 285: 2370-2375

3) Inoue H, Fujiki A, Origasa H, Ogawa S, Okumura K, Kubota I, Aizawa Y, Yamashita T, Atarashi H, Horie M, Ohe T, Doi Y, Shimizu A, Chishaki A, Saikawa T, Yano K, Kitabatake A, Mitamura H, Kodama I, Kamakura S: Prevalence of atrial fibrillation in the general population of Japan: an analysis based on periodic health examination. Int J Cardiol 2009; 137: 102 107

4) Wolf PA, Abbott RD, Kannel WB: Atrial fibrillation as an independent risk factor for stroke: the Framingham Study. Stroke 1991; 22: 983-988
5）小川 聡, 相澤義房, 新 博次, 井上 博, 奥村 謙, 鎌倉史郎, 熊谷浩一郎, 是恒之宏, 杉薰, 三田村秀雄, 矢坂正弘, 山下武志, 大江 透, 児玉逸雄, 比江嶋一昌, 矢野捷介 : 循環器病の診断と治 療に関するガイドライン (2006-2007 年度合同研究班報 告) 心房細動治療(薬物) ガイドライン. Cir J 2008; 72 (Suppl IV): 1581-1638

6) AFFIRM Investigators. Atrial Fibrillation Follow-up Investigation of Rhythm Management: Baseline characteristics of patients with atrial fibrillation: the AFFIRM Study. Am Heart J 2002; 143: 991-1001

7) Weijs B, Pisters R, Haest RJ, Kragten JA, Joosen IA, Versteylen M, Timmermans CC, Pison L, Blaauw Y, Hofstra L, Nieuwlaat R, Wildberger J, Crijns HJ: Patients originally diagnosed with idiopathic atrial fibrillation more often suffer from insidious coronary artery disease compared to healthy sinus rhythm controls. Heart Rhythm 2012; 9: 1923-1929

8) Yamashita T, Ogawa S, Aizawa Y, Atarashi H, Inoue H, Ohe T, Okumura K, Kato T, Kamakura S, Kumagai K, Kurachi Y, Kodama I, Koretsune Y, Saikawa T, Sakurai M, Sugi K, Nakaya H, Nakayama T, Hirai M, Fukatani M, Mitamura H, Yamazaki T; J-RHYTHM Investigators: Investigation of the optimal treatment strategy for atrial fibrillation in Japan. Circ J 2003; 67: 738-741

9) Krahn AD, Manfreda J, Tate RB, Mathewson FA, Cuddy TE: The natural history of atrial fibrillation: incidence, risk factors, and prognosis in the Manitoba Follow-Up Study. Am J Med 1995; 98: 476-484

10）奥村 謙, 相澤義房, 青沼和隆, 磯部文隆, 大西 哲, 加藤貴雄, 清水昭彦, 新田 隆, 萩原誠久, 松本万夫, 村川裕二, 石川利之, 岩亨, 梅村 純, 草野研吾, 栗田隆志, 佐々木真吾, 志賀 剛, 庄田守男, 住友直方, 中里祐二, 中村好秀, 庭野慎一, 平尾見三, 大江 透, 笠貫 宏, 木村 剛, 児玉逸雄, 田中茂夫 : 循環器病の診断と治療に関するガイドライン (2010 年度 合同研究班報告) 不整脈の非薬物治療ガイドライン (2011 年改訂版)

11) Bando K, Kobayashi J, Hirata M, Satoh T, Niwaya K, Tagusari O, Nakatani S, Yagihara T, Kitamura S: Early and late stroke after mitral valve replacement with a mechanical prosthesis: risk factor analysis of a 24-year experience. J Thorac Cardiovasc Surg 2003; 126: 358-364

12) Bando K, Kasegawa H, Okada Y, Kobayashi J, Kada A, Shimokawa T, Nasu M, Nakatani S, Niwaya K, Tagusari O, Nakajima H, Hirata M, Yagihara T, Kitamura S: Impact of preoperative and postoperative atrial fibrillation on outcome after mitral valvuloplasty for nonischemic mitral regurgitation. J Thorac Cardiovasc Surg 2005; 129: 1032-1040

13) Prasad SM, Maniar HS, Camillo CJ, Schuessler RB, Boineau JP, Sundt TM, Cox JL, Damiano RJ: The Cox maze III procedure for atrial fibrillation: long-term efficacy in patients undergoing lone versus concomitant procedures. J Thorac Cardiovasc Surg 2003; 126: 1822-1828

14) Iwamura T, Kajimoto K, Yamamoto T, Yamasaki M, Tambara K, Yoneda Y, Amano A: Mid-term results for the Maze procedure 
in patients with non-mitral valvular atrial fibrillation. Ann Thorac Cardiovasc Surg 2011; 17: 356-362

15) Ad N, Cheng DC, Martin J, Berglin EE, Chang BC, Doukas G, Gammie JS, Nitta T, Wolf RK, Puskas JD: Surgical Ablation for Atrial Fibrillation in Cardiac Surgery: A Consensus Statement of the International Society of Minimally Invasive Cardiothoracic Surgery (ISMICS) 2009. Innovations (Phila) 2010; 5: $74-83$

16) Cheng DC, Ad N, Martin J, Berglin EE, Chang BC, Doukas G, Gammie JS, Nitta T, Wolf RK, Puskas JD: Surgical Ablation for Atrial Fibrillation in Cardiac Surgery: A Meta-Analysis and Systematic Review. Innovations (Phila) 2010; 5: 84-96

17) Calkins H, Kuck KH, Cappato R, Brugada J, Camm AJ, Chen SA, Crijns HJ, Damiano RJ Jr, Davies DW, DiMarco J, Edgerton J, Ellenbogen K, Ezekowitz MD, Haines DE, Haissaguerre M, Hindricks G, Iesaka Y, Jackman W, Jalife J, Jais P, Kalman J, Keane D, Kim YH, Kirchhof P, Klein G, Kottkamp H, Kumagai K, Lindsay BD, Mansour M, Marchlinski FE, McCarthy PM, Mont JL, Morady F, Nademanee K, Nakagawa H, Natale A, Nattel S, Packer DL, Pappone C, Prystowsky E, Raviele A, Reddy V, Ruskin JN, Shemin RJ, Tsao HM, Wilber D: 2012 HRS/EHRA/ECAS Expert Consensus Statement on Catheter and Surgical Ablation of Atrial Fibrillation: recommendations for patient selection, procedural techniques, patient management and follow-up, definitions, endpoints, and research trial design. Europace 2012; 14: 528-606

18) Rogers CA, Angelini GD, Culliford LA, Capoun R, Ascione R: Coronary surgery in patients with preexisting chronic atrial fibrillation: early and midterm clinical outcome. Ann Thorac Surg 2006; 81: 1676-1682

19) Ngaage DL, Schaff HV, Mullany CJ, Sundt TM, Dearani JA, Barnes S, Daly RC, Orszulak TA: Does preoperative atrial fibrillation influence early and late outcomes of coronary artery bypass grafting? J Thorac Cardiovasc Surg 2007; 133: 182-189

20) Banach M, Goch A, Misztal M, Rysz J, Zaslonka J, Goch JH, Jaszewski R: Relation between postoperative mortality and atrial fibrillation before surgical revascularization-3-year follow-up. Thorac Cardiovasc Surg 2008; 56: 20-23

21) Fukahara K, Kotoh K, Doi T, Misaki T, Sumi S: Impact of preoperative atrial fibrillation on the late outcome of off-pump coronary artery bypass surgery. Eur J Cardiothorac Surg 2010; 38: $366-372$

22) Damiano RJ, Gaynor SL, Bailey M, Prasad S, Cox JL, Boineau JP, Schuessler RP: The long-term outcome of patients with coronary disease and atrial fibrillation undergoing the Cox maze procedure. J Thorac Cardiovasc Surg 2003; 126: 2016-2021

23) Khargi K, Lemke B, Haardt H, Müller KM, Mügge A, Laczkovics A, Deneke T: Concomitant anti-arrhythmic surgery, using irrigated cooled-tip radiofrequency ablation, to treat permanent atrial fibrillation in CABG patients: expansion of the indication? Eur J Cardiothorac Surg 2004; 25: 1018-1024

24) Gaynor SL, Ishii Y, Diodato MD, Prasad SM, Barnett KM, Damiano NR, Byrd GD, Wickline SA, Schuessler RB, Damiano RJ: Successful performance of Cox-Maze procedure on beating heart using bipolar radiofrequency ablation: a feasibility study in animals. Ann Thorac Surg 2004; 78: 1671-1677

25) Suwalski P, Suwalski G, Doll N, Majstrak F, Kurowski A, Suwalski KB: Epicardial beating heart "off-pump" ablation of atrial fibrillation in non-mitral valve patients using new irrigated bipolar radiofrequency technology. Ann Thorac Surg 2006; 82: 1876-1879

26) Akpinar B, Sanisoglu I, Guden M, Sagbas E, Caynak B, Bayramoglu Z: Combined off-pump coronary artery bypass grafting surgery and ablative therapy for atrial fibrillation: early and mid-term results. Ann Thorac Surg 2006; 81: 1332-1337

27) Balasubramanian SK, Theologou T, Birdi I: Microwave surgical ablation for atrial fibrillation during off-pump coronary artery surgery using total arterial-Y-grafts: an early experience. Interact Cardiovasc Thorac Surg 2007; 6: 447-450

28) Groh MA, Binns OA, Burton HG 3rd, Champsaur GL, Ely SW, Johnson AM: Epicardial ultrasonic ablation of atrial fibrillation during concomitant cardiac surgery is a valid option in patients with ischemic heart disease. Circulation 2008; 118 (14 Suppl): S78-S82

29) Haïssaguerre M, Jaïs P, Shah DC, Takahashi A, Hocini M, Quiniou G, Garrigue S, Le Mouroux A, Le Métayer P, Clémenty J: Spontaneous initiation of atrial fibrillation by ectopic beats originating in the pulmonary veins. N Engl J Med 1998; 339: 659-666

30) Fukahara K, Doi T, Yamashita S, Kotoh K, Misaki T: [Current status and prospect of off-pump pulmonary vein isolation for atrial fibrillation]. Kyobu Geka 2010; 63: 284-289(in Japanese)

31) Salzberg SP, Plass A, Emmert MY, Desbiolles L, Alkadhi H, Grünenfelder J, Genoni M: Left atrial appendage clip occlusion: early clinical results. J Thorac Cardiovasc Surg 2010; 139: $1269-1274$

32) Ailawadi G, Gerdisch MW, Harvey RL, Hooker RL, Damiano RJ Jr, Salamon T, Mack MJ: Exclusion of the left atrial appendage with a novel device: early results of a multicenter trial. J Thorac Cardiovasc Surg 2011; 142: 1002-1009, 1009.e1

33) Starck CT, Steffel J, Emmert MY, Plass A, Mahapatra S, Falk V, Salzberg SP: Epicardial left atrial appendage clip occlusion also provides the electrical isolation of the left atrial appendage. Interact Cardiovasc Thorac Surg 2012; 15: 416-418

34) Wolf RK, Schneeberger EW, Osterday R, Miller D, Merrill W, Flege JB, Gillinov AM: Video-assisted bilateral pulmonary vein isolation and left atrial appendage exclusion for atrial fibrillation. J Thorac Cardiovasc Surg 2005; 130: 797-802

35) Kasirajan V, Spradlin EA, Mormando TE, Medina AE, Ovadia P, Schwartzman DS, Gaines TE, Mumtaz MA, Downing SW, Ellenbogen KA: Minimally invasive surgery using bipolar radiofrequency energy is effective treatment for refractory atrial fibrillation. Ann Thorac Surg 2012; 93: 1456-1461

36) Totsugawa $T$, Kuinose M, Nishigawa K, Yoshitaka H, Tsushima $Y$, Ishida A: Minimally invasive cardiac surgery for atrial fibrillation complicated by coronary artery disease: combination of video-assisted pulmonary vein isolation and minimally invasive direct coronary artery bypass. Gen Thorac Cardiovasc Surg 2009; 57: 612-615 